\title{
ENVOLVIMENTO dO CLIENTE E GESTÃo ÁGIL DE PROJETOS INOVADORES: PERCEPÇÕES DE GESTORES DE PROJETOS EM AMBIENTE DE FÁBRICAS DE SOFTWARE
}

Ana Carolina dos Santos Paes (anacarolinads.paes@ gmail.com) - Universidade Federal de Minas Gerais (UFMG)

Raoni Barros Bagno (rbbagno@gmail.com) - Universidade Federal de Minas Gerais (UFMG)

\section{RESUMO}

Nas últimas décadas, novas abordagens de gerenciamento de projetos têm se consolidado, como os métodos chamados “ágeis", que estão se difundindo rapidamente no contexto de desenvolvimento de software. Embora suas vantagens estejam em evidência, existem desafios sobre o envolvimento do cliente neste tipo de projeto. No caso de projetos realizados com clientes atraídos mais recentemente de setores considerados tradicionais (por exemplo, advogados), a aplicação de métodos ágeis pode gerar conflitos relacionados aos pressupostos típicos destes métodos sobre o papel e o comportamento do cliente. Com base nessas questões, este artigo tem como objetivo identificar a percepção dos gestores de projetos de fábricas de software a respeito de como estes novos clientes lidam com a gestão ágil. Para isso, foram realizadas entrevistas com três gestores do setor de tecnologia da informação. Como resultado, foram identificadas dificuldades centrais por parte de clientes desses gestores para aderir aos métodos ágeis, além de cinco estratégias usadas pelos gestores para lidar com tais dificuldades. Palavras-chave: métodos ágeis; envolvimento do cliente; colaboração do cliente; gestão de projetos; desenvolvimento de software. 


\section{INTRODUÇÃO}

Em décadas recentes, observa-se o gradual reconhecimento de particularidades associadas a projetos inovadores na área de software, que não se encaixam adequadamente nas premissas típicas que nortearam o campo do gerenciamento de projetos até então. Muito do que fora proposto neste campo de conhecimento pautava-se no contexto de projetos de baixas incertezas/alta previsibilidade que permitiam o trabalho com escopo fechado, plano detalhado e com forte viés de controle. Desde os anos 2000, o destaque dado a tais particularidades tem colaborado para o surgimento de novas abordagens de gerenciamento de projetos (Amaral et al., 2011). Dessa forma, métodos chamados "ágeis" têm se desenvolvido e se difundido rapidamente dentro e fora do contexto de desenvolvimento de software.

Muito embora as vantagens e a acelerada difusão dos métodos ágeis de desenvolvimento sejam inegáveis no debate amplo de projetos inovadores, tais abordagens carregam consigo fortes pressupostos e desafios sobre o envolvimento do cliente neste tipo de projeto, assim como sobre seu comportamento e expectativas. Alguns dos pressupostos e desafios, abordados por Hoda, Noble e Marshall (2010), são: a colaboração do cliente e o feedback rápido, que são de vital importância em projetos ágeis que envolvem incertezas; clientes que desejam os benefícios divulgados da gestão ágil, mas não compreendem inteiramente como essa gestão funciona, de forma a causar complicações durante a execução; alguns clientes não estão tão envolvidos em projetos de gestão ágil ou não estão dispostos no nível que os métodos ágeis exigem.

A gestão ágil costuma apresentar alguns desafios no que se refere a sua operacionalização durante a interação com o cliente. Com a grande difusão das tecnologias digitais, as oportunidades de desenvolvimento e de aplicação de software para setores de serviços considerados mais tradicionais estão cada vez mais em evidência. Há alguns anos, setores da área jurídica, por exemplo, tinham poucas interações com tecnologias mais avançadas. Dessa forma, ao mesmo tempo em que este crescimento contribui para a expansão das aplicações de 
software, emerge um ponto de conflito potencial em relação aos pressupostos ágeis, que já vinham evoluindo ao longo dos anos em outras áreas, mas que não eram totalmente conhecidos nas áreas mais tradicionais. Neste trabalho, iremos nos referir a clientes de áreas mais tradicionais como clientes “cascata” e clientes de áreas que compreendem há mais tempo sobre tecnologia, de clientes “ágeis”. Segundo Hoda, Noble e Marshall (2009a), os clientes “cascata” estão acostumados à gestão tradicional de projetos, não compreendendo inteiramente como a gestão ágil funciona. Apesar destes clientes apresentarem potencial para o desenvolvimento de novas tecnologias, tende a predominar um mindset voltado para a previsibilidade e o controle. Este é um dos pressupostos/desafios que a gestão ágil compreende e que pode atrapalhar a sua aplicação, causando insatisfação do cliente "cascata" e até insucesso em projetos.

Diante dessas questões, este artigo tem como objetivo identificar a percepção dos gestores de projetos de fábricas de software a respeito de como os clientes "cascata" lidam com a gestão ágil de projetos. Dessa forma, esse trabalho contribui no sentido de fomentar as iniciativas e estratégias que possam identificar melhor este perfil de cliente, harmonizando abordagens de gestão, garantindo entregas com maior satisfação para os clientes e ampliando oportunidades para novos mercados de produtos de software.

\section{REVISÃO TEÓRICA}

\subsection{Envolvimento do cliente na gestão ágil de projetos}

Atualmente, existem dois tipos de modelos de gerenciamento de projetos que são mais difundidos: o modelo tradicional e o modelo ágil de gestão de projetos. O primeiro está diretamente relacionado às abordagens de gestão em que são criados planos detalhados e que é necessário controlá-los. Já o gerenciamento ágil de projetos, segundo Highsmith (2012), é definido como um conjunto de princípios, valores e práticas que auxiliam a equipe de projetos a entregar produtos ou serviços de valor em um ambiente de projetos desafiador. As principais 
características que diferem abordagens ágeis do que hoje é chamado de gestão tradicional são: a simplificação dos métodos tradicionais, o planejamento interativo e incremental, o aumento da autonomia dos membros do projeto nas atividades de gerenciamento, a alta incerteza e imprevisibilidade que o projeto detém. Em projetos de software, a abordagem mais frequentemente adotada nos últimos anos é a gestão ágil de projetos, em função das mudanças e incertezas que caracterizam o desenvolvimento de inovações neste setor.

Segundo Amaral et al. (2011), a alta adesão aos métodos ágeis tem ocorrido ao ponto de a abordagem sofrer contínuas interpretações e adaptações. Desde que preservados seus pressupostos centrais, tais métodos tornam-se aplicáveis a diversos ambientes distintos de seu contexto original de proposição, de forma a carregar a inovação e flexibilidade de mudanças em seu eixo central. O próprio corpo de conhecimento da gestão de projetos tradicional $(P M B O K)$ tem sido revisitado e atualizado para contemplar os importantes avanços realizados neste campo. A literatura ágil sugere que a participação ativa/contínua e o envolvimento dos clientes ao longo do projeto são a chave para construir o produto certo e aumentar a satisfação dos usuários (BAKALOVA; DANEVA, 2011).

Entretanto, mesmo os profissionais afirmando que as práticas ágeis representam uma mudança de paradigma significativa para a indústria de software nos últimos tempos, os clientes muitas vezes as rejeitam como apenas mais uma nova palavra da moda (HODA; NOBLE; MARSHALL, 2009a). Esses autores ainda destacam que alguns dos princípios da gestão ágil não são compreendidos tão prontamente pelos clientes como era originalmente pretendido e suscitam preocupações por parte do cliente.

No estudo de Hoda, Noble e Marshall (2011), nota-se que alguns clientes não estão tão envolvidos em projetos de gestão ágil ou não estão dispostos no nível que os métodos ágeis exigem, embora desejem os benefícios típicos da gestão ágil como entregas frequentes, 
alteração de escopo e feedback rápido. Os participantes do estudo identificaram várias causas para a falta de envolvimento do cliente, incluindo: o fator distância, a falta de comprometimento de tempo, a forma de lidar com grandes empresas que normalmente operam com processos de monitoramento e controle pré-definidos, os contratos de licitação fixa e os representantes ineficazes do cliente. Além disso, o envolvimento inadequado do cliente nesses projetos ágeis levou a consequências adversas para as equipes ágeis incluindo: problemas na coleta e no esclarecimento de requisitos, problemas na priorização de requisitos, problemas na proteção de feedback, perda de produtividade e até perda de negócios. Neste mesmo estudo, os autores sugerem algumas soluções para aplicar o método ágil com os clientes, são elas: mudança da mentalidade dos clientes; oferecimento de diferentes opções de contrato a fim de incentivá-los a experimentar o ágil; inserção de buffer embutido para incertezas (recurso a mais, reservado no projeto, caso seja necessária a inserção de mais recursos do que o esperado), também mencionado por Deemer et al. (2007); avaliação de risco antecipada; sugestão de proprietários de histórias, que é uma adaptação dos Product owners que a metodologia Scrum sugere; aplicação do Ágil Undercover, onde o método ágil é aplicado apenas para os membros internos do projeto, mas com uma "embalagem" externa que omite sua real forma ao cliente.

Além destes autores, Deemer et al. (2007) comentam que a abordagem cascata de gestão de projetos requer que todas as boas ideias surjam no início do ciclo de lançamento, onde podem ser incorporadas ao plano. Porém, boas ideias aparecem ao longo do processo e se este não permite mudanças, irá sufocar essa inovação. Com a cascata, uma ótima ideia no final do ciclo de lançamento não é um presente, mas uma ameaça.

\section{METODOLOGIA}

A metodologia deste trabalho pode ser melhor entendida com base na FIGURA 1. Inicialmente, foi realizada a compreensão do problema abordado pelos autores. Um dos pesquisadores 
autores deste trabalho é gerente de projetos em uma fábrica de software e trouxe um caso para dar suporte na análise alguns problemas e questões que ele tem se deparado na empresa que gerencia. Dessa forma, o problema começou a ser compreendido e delineado e, em seguida, foram realizadas buscas nas bases de pesquisa mais renomadas, como Web of Science e Scielo. Também foram realizadas buscas de artigos em journals que são referência em gestão ágil de projetos, como o International Journal of Project Management e o Journal of Engineering and Technology Management.

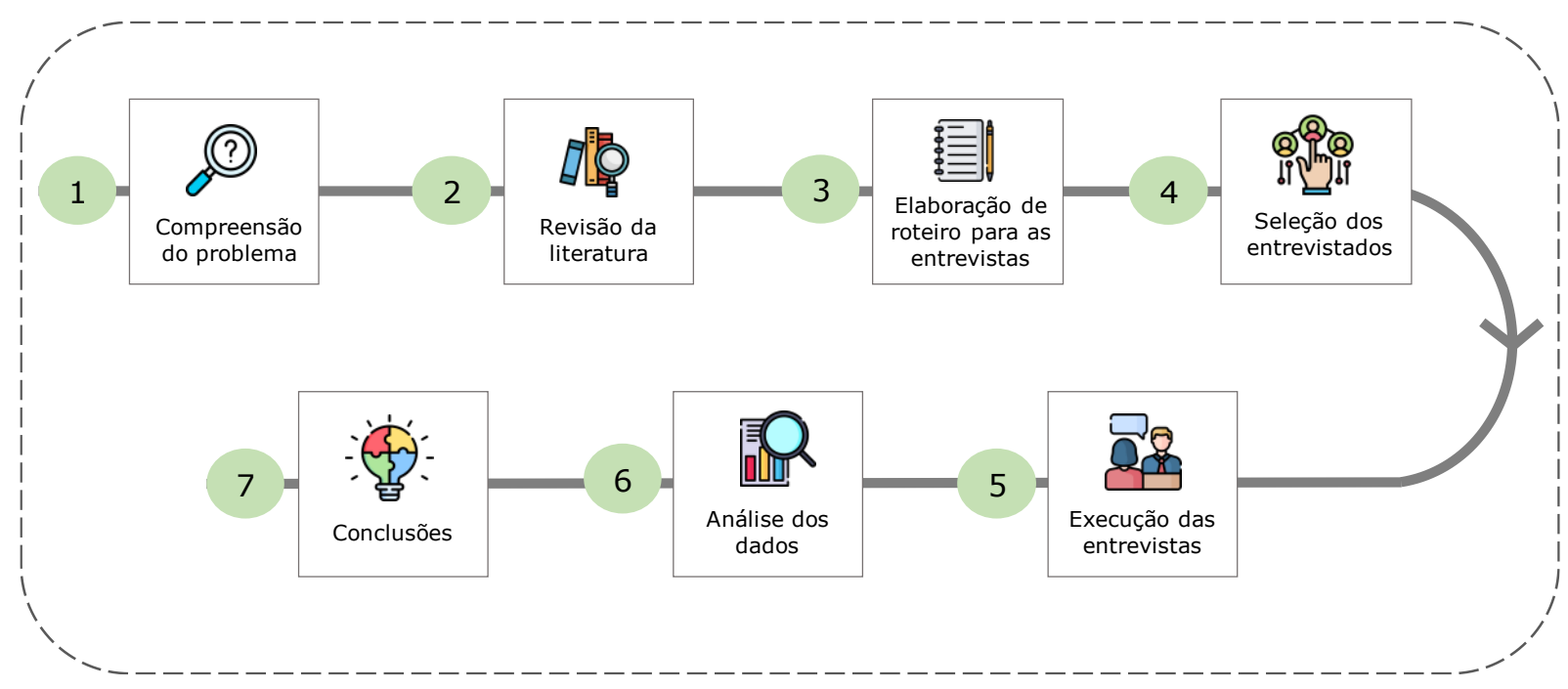

FIGURA 1 - Metodologia de pesquisa. Fonte: Elaborado pelos autores

Tendo sido o problema bem delineado e realizada uma aquisição de buscas relevantes na literatura, foi desenvolvido um roteiro para as entrevistas. Neste, primeiramente foi escrita uma introdução sobre o tema de pesquisa, no qual havia questões que a pesquisadora identificou no seu trabalho como gestora, somado às questões identificadas na busca da literatura. Esta introdução continha alguns pontos a serem abordados nas entrevistas, como o gerenciamento de mudanças em ambiente ágil, mudanças no escopo do projeto, falta de priorização do que deve ser desenvolvido por parte do cliente. O principal objetivo deste tópico era entender se o entrevistado também reconheceria como problema aquilo que foi identificado previamente. Também foram delineadas algumas perguntas para guiar a entrevista, com temas sobre o 
funcionamento do processo de gestão e desenvolvimento ágil na empresa, priorização dos itens de desenvolvimento no projeto e entendimento do ambiente ágil por parte do cliente.

Posteriormente foi necessário selecionar quais seriam os entrevistados da pesquisa. Foram selecionados 3 gestores de projetos de fábricas de software distintas, gestores M, R e L. Eles lideram equipes de desenvolvimento neste tipo de empresa e tem de 2 a 10 anos de experiência com gestão. Cada entrevista durou aproximadamente 45 minutos e foram gravadas. Estas foram realizadas separadamente e, durante a sua execução, os entrevistados foram confrontados primeiramente em relação a sua experiência geral e, após isto, ficaram livres para contar sobre suas questões como gestores. Durante a entrevista, eles apresentaram alguns exemplos específicos já vivenciados por eles sobre a abordagem da gestão ágil, com vários tipos de clientes, e todos os três gestores reconheceram o problema de pesquisa estudado, citando que os clientes não estão acostumados com a gestão ágil de projetos. Dois dos entrevistados citaram que existe um tipo de cliente que pertence às áreas tradicionais (clientes do tipo "cascata", como são citados neste trabalho) e não estão tão acostumados com tecnologia, se comparados a clientes típicos de áreas tecnológicas.

Após a realização das três entrevistas, elas foram transcritas para ajudar na análise e na compilação dos resultados. Inicialmente foram identificados 7 grupos de afinidade a partir das respostas dos entrevistados. Os tópicos foram inseridos em uma planilha, juntamente com as frases de cada entrevistado, e foi montado um quadro-síntese das entrevistas. Logo após, foi gerado um resumo com várias informações agrupadas e organizadas, o que resultou na identificação de três dificuldades centrais por parte de clientes ao aderir aos métodos ágeis e cinco estratégias usadas pelos gestores para lidar com o problema do ágil perante o cliente.

\section{RESULTADOS E DISCUSSÃO}

\subsection{Análise dos resultados das entrevistas}


Após a análise das entrevistas, foi elaborada a avaliação destas com base no referencial teórico do artigo apresentado. Nas entrevistas, três dificuldades por parte de clientes ao aderir aos métodos ágeis foram mencionadas mais destacadamente: falta de compreensão da metodologia ágil, área de atuação do cliente e mudanças/incertezas do ágil. Além das dificuldades encontradas, os gestores mencionaram as estratégias usadas para lidar com o problema do ágil perante o cliente: alinhamento do escopo do projeto, inserção de buffer (margem de segurança), estabelecimento da priorização do projeto, elaboração de termo aditivo no contrato e, por fim, aproximação dos gestores ao cliente. Cada um destes fatores será detalhado nos tópicos subsequentes.

\subsubsection{Dificuldades por parte de clientes ao aderir aos métodos ágeis}

\section{- Falta de compreensão da metodologia ágil}

Durante as entrevistas, pode-se perceber que os gestores $\mathrm{M}$ e $\mathrm{R}$ identificam falta de entendimento da metodologia ágil por parte dos clientes "cascata" nos projetos desenvolvidos. Isso fica evidente principalmente pelo entrevistado $\mathrm{R}$, que menciona as mudanças da prioridade de clientes a todo momento durante o desenvolvimento de projetos. Ele afirma que alguns clientes não entendem o que é o ágil e acreditam que "deve-se jogar toda a documentação fora". Porém, para o gestor R, o ágil facilita a visualização do projeto e a satisfação do cliente é maior nesse tipo de gestão, pois o envolvimento com o cliente é mais significativo e a validação constante colabora para o desenvolvimento de acordo com o desejado. É importante ressaltar que na metodologia ágil deve haver documentação do projeto, mas se comparada à gestão tradicional de projetos, esta costuma ser menor.

\section{- Área de atuação do cliente}

Os gestores entrevistados afirmam que os clientes que não são da área de tecnologia (como por exemplo clientes da área jurídica), apresentam dificuldade para lidar com mudanças durante o projeto e que para os que compreendem e trabalham com tecnologia, as mudanças necessárias 
são mais fáceis de serem compreendidas. Segundo o entrevistado M, "se a pessoa não tem experiência técnica com tecnologia, vai ser mais difícil lidar com questões de software”. Da mesma forma, o entrevistado R comenta que "a experiência do cliente ajuda a não alterar o escopo".

Além disso, segundo o entrevistado L, após algum tempo de experiência e de identificação por parte da empresa, alguns projetos geravam mais sucesso do que outros em função da área do cliente, devido a isso, a empresa optou pela inserção de um filtro na captação de clientes. Esta capta, em sua maioria, clientes que compreendiam mais de tecnologia. Segundo ele, "a empresa começou a filtrar clientes mais técnicos e que entendiam mais as mudanças, porque seria mais simples a compreensão do projeto ágil se os clientes entendessem as mudanças”.

\section{- Mudanças/incertezas no ágil}

O entrevistado M comenta que "o cliente acha que o ágil é flexível, mas não entende que o projeto de software é frequentemente caracterizado por mudanças e incertezas ao longo de seu desenvolvimento". A flexibilidade na gestão ágil ocorre ao identificar, por exemplo, após o cliente visualizar uma parte do produto, que este não cumpria com o necessário e, assim, um produto com outras características era desenvolvido, tendo o anterior como base. Além disso, o entrevistado M comenta que a metodologia ágil de projetos facilita a visualização do produto em funcionamento para o cliente, o que gera uma maior satisfação e envolvimento com o mesmo.

\subsubsection{Estratégias dos gestores para lidar com o problema do ágil perante o cliente}

\section{- Alinhamento do escopo do projeto}

Em projetos que envolvem gerenciamento ágil, o escopo geralmente não é fixo, podendo haver alterações durante o desenvolvimento. Porém, muitas alterações em um mesmo projeto podem comprometer o prazo e o objetivo do mesmo. Segundo os entrevistados, alteração de escopo durante o projeto são comuns e, em alguns casos, os clientes apresentam dificuldade para 
entender o que é preciso ser desenvolvido. Por isso, o entrevistado $\mathrm{M}$ afirma: "se o cliente sabe o que quer, o escopo é fechado e não precisa de grandes mudanças". Já o entrevistado L comenta que é de grande importância a realização de reunião para detalhamento do escopo no contrato para sanar dúvidas com relação ao design do produto e ao processo.

O entrevistado $\mathrm{M}$ afirma que, em alguns casos, onde existe maior confiança entre as partes, não são elaborados contratos e os projetos costumam sofrer alterações no escopo a todo momento. Segundo os gestores, geralmente isso ocorre pelo fato de o cliente não saber o que quer desenvolver, pois só tem a ideia central em mente.

\section{- Inserção de buffer (margem de segurança) em projetos}

Incertezas costumam fazer parte de projetos que envolvem tecnologia, como no caso de fábricas de software. Em função disso, os três entrevistados afirmaram inserir uma margem de segurança (buffer) em orçamentos de projetos em função de possíveis mudanças e incertezas. Dessa forma, se for necessário aumentar o valor do projeto em função da adição de tempo ou escopo, o projeto apresenta capacidade para isso. Segundo o entrevistado L, "a mudança é algo inerente ao projeto", ou seja, é necessário estar preparado para ela.

\section{- Elaboração de priorização do projeto}

Segundo os entrevistados M e L, se a margem inserida não for suficiente para suportar as mudanças e as incertezas, uma priorização do escopo é sugerida aos clientes, de forma a identificar o que é realmente prioritário para o mesmo, tendo um foco específico no projeto ao invés de ter vários focos. Um ponto importante relatado pelos dois entrevistados foi que os clientes acreditam que tudo é prioritário e apresentam dificuldade em relatar o que é fundamental ou até mesmo, como mencionado pelo gestor R: “o cliente não sabia o que queria”.

\section{- Elaboração de termo aditivo no contrato}

Segundo os três entrevistados, se a priorização de itens não for suficiente para mitigar as incertezas, um termo aditivo é desenvolvido, de forma a cumprir com o que o cliente necessita, 
em função das mudanças ocorridas. Porém, segundo o entrevistado L, "se um contrato estratégico para a empresa necessitar de um termo aditivo, a equipe preferia gastar um pouco mais para desenvolver as alterações necessárias, não cobrando uma taxa a mais, visando uma renovação de contrato ou até mesmo a execução de um novo projeto".

\section{- Aproximação dos gestores ao cliente}

Segundo o entrevistado M, a aproximação da fábrica de software com o cliente faz com que este entenda as mudanças mais facilmente, se comparado a clientes que não têm muita proximidade com a equipe da fábrica. Segundo o entrevistado, "se a fábrica de software começar a dedicar mais horas para se aproximar do cliente, o projeto pode mudar de rumo, de forma que o cliente pode entender a mudança mais facilmente”. Além disso, o entrevistado acrescenta que projetos de incerteza desenvolvidos com pessoas já conhecidas pela equipe são mais fáceis de lidar do que com pessoas desconhecidas. Já o entrevistado L afirma que o contato diário com o cliente é de fundamental importância para o alcance do sucesso do projeto.

\subsection{Discussão dos resultados}

A FIGURA 2 exibe um quadro-síntese do que foi encontrado nas entrevistas, de forma a contribuir para uma melhor compreensão do trabalho. 


\begin{tabular}{|c|c|c|c|c|}
\hline & & Entrevistado M & Entrevistado $\mathbf{R}$ & Entrevistado L \\
\hline \multirow{3}{*}{$\begin{array}{l}\text { Dificuldades por parte } \\
\text { de clientes ao aderir } \\
\text { aos métodos ágeis }\end{array}$} & $\begin{array}{l}\text { Falta de } \\
\text { compreensão da } \\
\text { metodologia ágil }\end{array}$ & $\begin{array}{l}\text { Falta de entendimento da metodologia } \\
\text { ágil por parte dos clientes }\end{array}$ & \begin{tabular}{|c|} 
Alguns clientes não entendem o que é o \\
ágil e acreditam que "deve-se jogar \\
toda a documentação fora"
\end{tabular} & $\begin{array}{l}\text { Mudança de ideias dos clientes é algo } \\
\text { muito comum }\end{array}$ \\
\hline & $\begin{array}{l}\text { Área de atuação do } \\
\text { cliente }\end{array}$ & $\begin{array}{c}\text { Cliente que não tem experiência técnica } \\
\text { com tecnologia costuma ter mais } \\
\text { dificuldade para lidar com questões de } \\
\text { software }\end{array}$ & $\begin{array}{l}\text { A experiência do cliente ajuda a não } \\
\text { alterar o escopo }\end{array}$ & $\begin{array}{c}\text { A empresa começou a filtrar clientes } \\
\text { mais técnicos e que entendiam mais as } \\
\text { mudanças, porque seria mais simples a } \\
\text { compreensão de projetos ágeis }\end{array}$ \\
\hline & $\begin{array}{c}\text { Mudanças/incertezas } \\
\text { do ágil }\end{array}$ & \begin{tabular}{|} 
Ágil facilita a visualização do produto \\
em funcionamento para o cliente, o que \\
gera uma maior satisfação e \\
envolvimento do mesmo
\end{tabular} & $\begin{array}{l}\text { Mudanças a todo o momento } \\
\text { compromete o escopo do projeto }\end{array}$ & $\begin{array}{c}\text { Mudança de ideias dos clientes a todo } \\
\text { o momento é algo muito comum nos } \\
\text { projetos da fábrica de software }\end{array}$ \\
\hline \multirow{5}{*}{$\begin{array}{c}\text { Estratégias dos } \\
\text { gestores para lidar com } \\
\text { o problema do ágil } \\
\text { perante o cliente }\end{array}$} & $\begin{array}{l}\text { Alinhamento do } \\
\text { escopo do projeto }\end{array}$ & $\begin{array}{l}\text { Em alguns casos, onde existe maior } \\
\text { confiança entre as partes, não são } \\
\text { elaborados contratos e os projetos } \\
\text { costumam sofrer alterações no escopo } \\
\text { a todo momento }\end{array}$ & $\begin{array}{l}\text { Muitas vezes ocorre do cliente não } \\
\text { saber o que quer no projeto }\end{array}$ & $\begin{array}{c}\text { É de grande importância a realização } \\
\text { de reunião para detalhamento do } \\
\text { escopo no contrato para sanar dúvidas } \\
\text { com relação ao design do produto e ao } \\
\text { processo }\end{array}$ \\
\hline & $\begin{array}{l}\text { Inserção de buffer } \\
\text { (margem de } \\
\text { segurança) em } \\
\text { projetos }\end{array}$ & $\begin{array}{l}\text { Se a margem inserida não for suficiente } \\
\text { para suportar as mudanças e as } \\
\text { incertezas, uma priorização do escopo } \\
\text { era sugerida para os clientes }\end{array}$ & $\begin{array}{c}\text { Uso de uma margem de segurança para } \\
\text { as mudanças que poderiam vir a } \\
\text { ocorrer }\end{array}$ & $\begin{array}{l}\text { Se a margem inserida não for suficiente } \\
\text { para suportar as mudanças e as } \\
\text { incertezas, uma priorização do escopo } \\
\text { era sugerida para os clientes }\end{array}$ \\
\hline & $\begin{array}{l}\text { Elaboração de } \\
\text { priorização do } \\
\text { projeto }\end{array}$ & $\begin{array}{l}\text { Os clientes acreditam que tudo é } \\
\text { prioritário e apresentam dificuldade em } \\
\text { relatar o que é fundamental para ser } \\
\text { desenvolvido }\end{array}$ & $\begin{array}{l}\text { Mudança da prioridade do cliente a } \\
\text { todo momento }\end{array}$ & $\begin{array}{l}\text { Os clientes acreditam que tudo é } \\
\text { prioritário e apresentam dificuldade em } \\
\text { relatar o que é fundamental para ser } \\
\text { desenvolvido }\end{array}$ \\
\hline & $\begin{array}{c}\text { Elaboração de termo } \\
\text { aditivo no contrato }\end{array}$ & $\begin{array}{c}\text { Adição de termo ao contrato para } \\
\text { executar o que estiver fora do escopo } \\
\text { no projeto }\end{array}$ & $\begin{array}{c}\text { Adição de termo ao contrato para } \\
\text { executar o que estiver fora do escopo } \\
\text { no projeto }\end{array}$ & $\begin{array}{l}\text { Se um contrato estratégico para a } \\
\text { empresa necessitar de um termo } \\
\text { aditivo, a equipe preferia gastar um } \\
\text { pouco mais de recursos para } \\
\text { desenvolver as alterações necessárias }\end{array}$ \\
\hline & $\begin{array}{l}\text { Aproximação dos } \\
\text { gestores ao cliente }\end{array}$ & $\begin{array}{l}\text { Se a fábrica de software começar a } \\
\text { dedicar mais horas para se aproximar } \\
\text { do cliente, o projeto pode mudar de } \\
\text { rumo, de forma que o cliente pode } \\
\text { entender a mudança mais facilmente } \\
\text { Projetos de incerteza desenvolvidos } \\
\text { com pessoas já conhecidas pela equipe } \\
\text { são mais fáceis de lidar do que com } \\
\text { pessoas desconhecidas }\end{array}$ & $\begin{array}{c}\text { Com as interações do ágil, o cliente fica } \\
\text { mais satisfeito ao ver o projeto em } \\
\text { desenvolvimento }\end{array}$ & $\begin{array}{c}\text { O contato diário com o cliente é de } \\
\text { fundamental importância para o alcance } \\
\text { do sucesso do projeto }\end{array}$ \\
\hline
\end{tabular}

FIGURA 2 - Síntese das entrevistas relacionadas aos pontos em comum dos gestores. Fonte: Elaborado pelos autores 
Um dos importantes fatores percebidos nas entrevistas foi a falta de compreensão do método ágil, em função de alguns clientes não entenderem como este deve ser utilizado, como mencionado por Hoda, Noble e Marshall (2009), além de não compreenderem as mudanças/incertezas que este ambiente está envolto. Ademais, os gestores relatam sobre o tipo de cliente que se adequa menos ao ágil, que são os clientes "cascata". O ambiente destes é mais tradicional, onde a maioria não acompanha as mudanças tecnológicas, em comparação com as áreas de tecnologia. Isso tende a gerar um conflito de pensamentos, em função da diferença entre esses ambientes.

Em contrapartida, algumas estratégias para mitigar estas dificuldades foram relatadas pelos entrevistados. Estas estratégias são desenvolvidas de maneira informal, sem um guia ou um método por trás para nortear os gestores sobre a melhor forma de proceder com as dificuldades encontradas. Considerando que foram relatadas várias maneiras de mitigar os problemas mencionados, elas podem não ser totalmente eficazes, podendo comprometer até mesmo os próprios benefícios da metodologia ágil de projetos.

Este estudo trata-se de um levantamento preliminar, que faz parte de um estudo com pretensões mais amplas. Este levantamento traz insights iniciais sobre o reconhecimento de um problema que aparenta ser fortemente relevante para a expansão de soluções digitais de forma transversal na sociedade. Ademais, as estratégias adotadas pelos gestores entrevistados são bastante informais e, em uma primeira análise, evidenciam uma importante lacuna no que tange ao desenvolvimento de abordagens que permitam reconhecer as inadaptações do cliente às abordagens contemporâneas de desenvolvimento de produtos de base tecnológica. Além disso, o estudo aborda a proposição de formas mais apropriadas de harmonização das necessidades dos clientes com as formas de gestão de empresas de software. 


\section{CONCLUSÃO}

O presente artigo apresentou como proposta a identificação da percepção dos gestores de projetos de fábricas de software a respeito de como os clientes "cascata" lidam com a gestão ágil de projetos. No estudo foram identificadas três dificuldades por parte de clientes ao aderirem aos métodos ágeis: falta de compreensão da metodologia ágil, área de atuação do cliente e mudanças/incertezas do ágil. Também foram abordadas as estratégias dos gestores para mitigar o problema do ágil perante o cliente: alinhamento do escopo do projeto, inserção de buffer (margem de segurança) em projetos, estabelecimento da priorização do projeto, elaboração de termo aditivo no contrato e aproximação dos gestores com o cliente.

Foi percebido que clientes de ambientes tradicionais não costumam acompanhar as mudanças tecnológicas se comparados com clientes de áreas de tecnologia, o que tende a gerar conflitos quando os dois tipos de pensamentos interagem. Ademais, os clientes "cascata" costumam não entender bem incertezas e mudanças, o que gera dificuldades em projetos ágeis. As tentativas informais de mitigar as dificuldades enfrentadas podem comprometer os benefícios da metodologia ágil de projetos. Devido a isso, fica evidente a necessidade de estudos sobre formas de diminuir as dificuldades encontradas pelos gestores de projetos para lidar com clientes de contextos mais tradicionais.

\section{REFERÊNCIAS}

AMARAL, D. C.; CONFORTO, E. C.; BENASI, J. L. G.; ARAUJO, C. Gerenciamento ágil de projetos: aplicação em produtos inovadores. São Paulo: Saraiva, 2011.

BABB, J. S.; HODA, R.; NØRBJERG, J. Barriers to learning in agile software development projects. In: INTERNATIONAL CONFERENCE ON AGILE SOFTWARE DEVELOPMENT, 14., 2013, Vienna. Proceedings of International conference on agile software development. Heidelberg: Springer, Berlin, Heidelberg, 2013, p.1-15.

BAKALOVA, Z.; DANEVA, M. A Comparative case study on client's participation in a 'traditional' and in an Agile software company. In: INTERNATIONAL CONFERENCE ON PRODUCT FOCUSED SOFTWARE DEVELOPMENT AND PROCESS IMPROVEMENT, 12., 2011. Proceedings of the 12th International Conference on product focused software development and process improvement. DOI: https://doi.org/10.1145/2181101.2181118.

DEEMER, Pete et al. The scrum primer: an introduction to agile project management with scrum. Good Agile, Version,v.1, 2007. 
HIGHSMITH, J. Gerenciamento ágil de projeto: criando produtos inovadores. Traduzido por A. M. Toste. 2.ed. Rio de Janeiro: Alta Books, 2012.

HODA, R.; NOBLE, J.; MARSHALL, S. Don't Mention the 'A' word: agile undercover. Loca: Editora, 2009a

HODA, R.; NOBLE, J.; MARSHALL, S. Negotiating contracts for agile projects: a practical perspective. In: INTERNATIONAL CONFERENCE ON AGILE PROCESS AND EXTREME PROGRAMMING IN SOFTWARE ENGINEERING, 10., 2009b, Sardinia. Proceedings in Heidelberg: Springer, 2009b. p.186-191. (LNBIP, 31)

HODA, R.; NOBLE, J.; MARSHALL, S. Agile undercover: when customers don't collaborate. In: INTERNATIONAL CONFERENCE ON AGILE SOFTWARE DEVELOPMENT, 11., 2010, Trondheim. Proceedings in Heidelberg: Springer, 2010. p.73-87. (LNBIP, 48)

HODA, Rashina; NOBLE, James; MARSHALL, Stuart. THE impact of inadequate customer collaboration on self-organizing Agile teams. Information and Software Technology, v.53,n.5,p.521-534, 2011.

PROJECT MANAGEMENT INSTITUTE. PMBOK Guide: guide to the project management body of knowledge. Pennsylvania: Project Management Institute, 2004.

SERRADOR, Pedro; PINTO, Jeffrey K. Does Agile work? - a quantitative analysis of agile project success. International Journal of Project Management, v.33, n.5, p.1040-1051, 2015. 